\title{
PERAN CAREGIVER DALAM MENGENALKAN ANGGOTA TUBUH PADA INDIVIDU AUTISTIK USIA PRASEKOLAH
}

\author{
Diah Retno Anggraini \\ Program Studi Pendidikan Bahasa Inggris,Universitas Muhammadiyah Tangerang \\ Email: dieahr.anggraini@yahoo.com
}

\begin{abstract}
Abstrak
Diperkirakan sekitar 40.000-70.000 anak menjadi korban eksploitasi seks dan sekitar 100.000 anak diperdagangkan tiap tahun, hal ini merupakan bukti nyata kurangnya pengetahuan anak mengenai pendidikan seks yang seharusnya sudah mereka peroleh dari tahun pertama oleh caregivernya, dalam hal ini ibu. Memasuki usia 1-2 tahun, kemampuan berbicara, keingintahuan, serta kemampuan mengingat mulai meningkat dan cukup baik. Saat inilah yang tepat untuk terus menambah kosakata dan mengasah kemampuan anak dalam mengingat dan berbicara, dengan cara mulai mengenalkan bagian tubuh seperti rambut, hidung, lutut, tumit, dan sebagainya. Autisme merupakan suatu istilah yang digunakan untuk menggambarkan suatu jenis gangguan pervasive pada anak yang mengakibatkan gangguan atau keterlambatan pada bidang kognitif, bahasa, perilaku, komunikasi dan interaksi sosial. Memberikan pendidikan dan pemahaman merupakan tantangan sendiri bagi caregiver. Penelitian ini menggambarkan bagaimana peran yang dijalankan dan ditampilkan oleh caregiver (ibu) individu autis dalam memperkenalkan anggota tubuh. Metode yang digunakan dalam penelitian ini adalah metode kualitatif dengan pendekatan studi kasus dengan observasi dan wawancara yang dilakukan kepada caregiver dari individu autis. Hasil dari penelitian ini menunjukkan bahwa peran caregiver (ibu) yang maksimal menghasilkan perilaku individu autis yang mandiri. Mandiri dalam hal memahami anggota tubuh, menjaga kebersihan anggota tubuh dan memahami anggota tubuh yang boleh disentuh dan tidak boleh disentuh.
\end{abstract}

Kata Kunci: Autistik, Usia Prasekolah, Anggota Tubuh, Caregiver

\begin{abstract}
It is estimated that around 40,000-70,000 children become victims of sexual exploitation and about 100,000 children are trafficked each year. It clearly proves the children's lack of knowledge about sex education they should have gained in their first year from their caregivers, in this case their mothers. Entering the age of 1-2, children's curiosity and ability to speak and to remember begin to increase quite well. This is the right time to continuously enrich their vocabularies and hone their ability to remember and speak by introducing body parts like hair, nose, knees, heels, and so on. Autism is a term used to describe a type of pervasive disorder in a child resulting in a disturbance or delay in cognition, language, behavior, communication and social interaction. Providing education and understanding is a special challenge for caregivers. This study illustrates how the role performed and displayed by the caregiver (mother) of autistic individuals in introducing the parts of body. The method used in the study is a qualitative method with case study approach by conducting observation and interview with the caregiver of autistic children. The result of the study indicates that the full role of caregiver (mother) produces autistic children with independent behavior. They can understand their body parts, maintain the hygiene of body parts and understand what body parts that may be touched and not.
\end{abstract}

Keywords: Autistic, Preschool Age, Body Part, Caregiver

\section{PENDAHULUAN}

Diperkirakan sekitar 40.000-70.000 anak menjadi korban eksploitasi seks dan sekitar 100.000 anak diperdagangkan tiap tahun. Seorang anak lahir ibarat kertas kosong, belum tahu apa-apa. Caregiver sebagai orang terdekatnyalah yang bisa mengisinya. Banyak hal atau pelajaran yang harus diajarkan kepada anak. Salah satunya yaitu pengenalan anggota tubuh. Hal ini penting karena pada dasarnya anak memiliki perasaan seksual sejak lahir. Bayi 
sering menyentuh organ genitalnya karena mereka menimbulkan rasa "enak" atau menimbulkan rasa nyaman jika mereka sedang cemas dan marah.

Bayi satu tahun sudah mulai memainkan genitalnya saat diganti celananya dan kadang mereka juga memainkan feses nya saat dibersihkan. Hal ini wajar saja sebagai bagian dari rasa keingintahuan mereka. Anak usia prasekolah sering belum "aware" terhadap tubuhnya dan masih belum terlalu mengerti "malu" dalam keadaan telanjang.

Anak usia prasekolah tertarik untuk melihat tubuhnya sendiri dan tubuh temantemannya. Mereka sering bermain peran dokter-perawat sehingga mereka bisa saling melihat dan menyentuh satu sama lain. Mereka sering tertarik pada bagianbagian tubuh orang tuanya dan ingin menyentuhnya jika mereka kebetulan melihatnya di kamar atau di kamar mandi.

Mereka mulai tertarik konsep dari mana bayi berasal dan bagaimana bayi keluar dari perut ibunya. Sebelum usia 3 tahun, anak dapat menyampaikan jenis kelaminnya. Pada usia 6 tahun atau 7 tahun mereka mengerti bahwa organ genital bukanlah sesuatu yang bisa berubah lagi (laki berubah jadi perempuan, dan sebaliknya). Saat usia 4 tahun mereka sangat tertarik dengan hal-hal yang berhubungan dengan kamar mandi dan toilet.

Autisme merupakan suatu istilah yang digunakan untuk menggambarkan suatu jenis gangguan pervasive pada anak yang mengakibatkan gangguan atau keterlambatan pada bidang kognitif, bahasa, perilaku, komunikasi dan interaksi sosial. Prevalensi anak penyandang autis telah mengalami peningkatan yang sangat mengejutkan. Di Pensylvania, Amerika Serikat, jumlah anak-anak autisme saja dalam lima tahun terakhir meningkat sebesar 500\%, menjadi 40 dari 10.000 kelahiran.

Di Indonesia autisme pun mengalami peningkatan. Badan Pusat Statistik pada 2016 menunjukkan 4,6 juta anak adalah autisme. Orangtua yang memiliki anak autisme biasanya tidak mau menerima kondisi anaknya bahkan cenderung menolak. Reaksi orangtua beragam ketika mengetahui bahwa anaknya mengalami gangguan autism [1]. Terkejut, penyangkalan, tidak percaya, sedih, kecemasaan, menolak keadaan, perasaan tidak mampu dan malu, perasaan marah, bahkan ada perasaan bersalah dan berdosa adalah reaksi yang sering ditampilkan.

Fase perkembangan pada individu autis sama dengan individu normal [2]. Perlakuan pada individu autis seharusnya sama dengan individu normal. Perlakuan mulai diperkenalkan anggota tubuh sejak dini, perbedaan antara perempuan dan lakilaki agar mereka mempunyai pemahaman dan kemandirian, tetapi yang terjadi sebaliknya, orangtua yang seharusnya sebagai caregiver sibuk dengan perasaan tidak menerima yang pada akhirnya berdampak pada perkembangan individu autis. Orangtua merupakan sosok yang terpenting bagi individu autis, orangtua "mata" dan "tubuh" mereka.

Berdasarkan permasalahan di atas, maka penelitian ini untuk melihat bagaimana peran caregiver dalam hal ini ibudalam mengenalkan anggota tubuh pada individu autistik usia prasekolah.

\section{METODE}

Metode yang digunakan dalam penelitian ini adalah metode kualitatif dengan model pendekatan studi kasus (case study). Subjek penelitian dibagi menjadi dua, yakni subjek kasus dan subjek partisipan. Subjek kasus dalam penelitian ini adalah 
individu autis yang memasuki masa prasekolah, sedangkan subjek partisipan adalah caregiver (ibu individu autis).

Penelitian ini hanya melihat 2 kasus. Kasus pertama terdiri dari ibu dilatih; kasus kedua terdiri dari ibu tidak dilatih. Kriteria dilatih dan tidak dilatih dilihat dari segi aspek pendidikan. Teknik pengumpulan data yang digunakan adalah wawancara, observasi, dan review dokumen.

\section{HASIL DAN PEMBAHASAN}

Penelitian ini memfokuskan pada dua kasus, kasus pertama individu autistik dengan caregiver terlatih dan kasus kedua individu autistik dengan caregiver tidak terlatih. Kriteria terlatih dan tidak terlatih dinilai dari aspek pengetahuan, sikap dan perilaku. Hasil pemaparan setiap kasusnya dapat dilihat pada matriks peran caregiver dalam tabel 1 .

Tabel 1. Matriks Peran Caregiver

\begin{tabular}{|c|c|c|c|}
\hline \multicolumn{4}{|c|}{ Caregiver } \\
\hline & Pengetahuan & Sikap & Perilaku \\
\hline Kasus 1 & $\begin{array}{l}\text { - Mampu identifikasi adanya } \\
\text { keterhambatan perkembangan pada } \\
\text { anak sampai mampu identifikasi } \\
\text { bahwa keterhambatan itu } \\
\text { merupakan autis; mencari info } \\
\text { tentang autis dan penanganannya. } \\
\text { - Menerangkan tentang anggota } \\
\text { badan. } \\
\text { - Menerangkan tentang konsep } \\
\text { "pribadi"/“publik", mengajarkan } \\
\text { kemandirian. }\end{array}$ & $\begin{array}{l}\text { Menerima,dukungan (sikap } \\
\text { positif terhadap kehadiran } \\
\text { anaknya, seperti terus } \\
\text { mencari pengobatan, } \\
\text { menganggap anaknya } \\
\text { normal). }\end{array}$ & $\begin{array}{ll}\text { - } & \text { Model (panutan } \\
\text { bagi anaknya). } \\
\text { - } & \text { Membentuk } \\
\text { kemandirian } \\
\text { anaknya. }\end{array}$ \\
\hline Kasus 2 & $\begin{array}{l}\text { Minim (tidak mengetahui bahwa } \\
\text { ada keterlambatan perkembangan). }\end{array}$ & Penolakan & $\begin{array}{ll}\text { - } & \text { Memarah, } \\
\text { memukul. } \\
\text { - } \quad \text { Keinginan untuk } \\
\text { membuang anak. }\end{array}$ \\
\hline
\end{tabular}

Berdasarkan tabel di atas, dapat diketahui bahwa caregiver yang dilatih memiliki pengetahuan, sikap dan perilaku yang baik.Dalam hal ini caregiver memiliki pengetahuan yang baik, sikap dan perilaku sebagai role model bagi anaknya. Hal ini sejalan dengan apa yang diungkapkan oleh [2]. Caregiver (ibu) dilatih memiliki cara yang menyenangkan dan kreatif dalam mengajarkan anggota tubuh pada anaknya yang autistik, yaitu dengan cara:

\section{Bermain Tebak-Tebakan}

Permainan sederhana ini dilakukan oleh Caregiver (ibu) bersama anaknya kapan saja, misalnya saat makan siang. Caregiver (ibu) menanyakan kepada anaknya, "Kamu pegang sendok pakai apa, sayang?" Lalu, ibu membiarkan individu autis berusaha mengangkat tangannya, setiap berhasil mengangkat tangan ibu memberikan pujian serta diikuti dengan pelafalan "tangan" oleh ibu, setelah beberapa kali mengulangi pertanyaan serupa, individu autis akan makin terbiasa dan mampu mengingat, serta dapat mengucapkan "Tangan!", setiap anaknya berhasil mengucapkan kata tersebut, ibu selalu memberi pujian yang diikuti pelukan dan ciuman. Hal ini ibulakukan juga ketika akan mengenalkan bagian tubuh yang lain.

\section{Bernyanyi Bersama}

“Dua mata saya, hidung saya satu. "Lagu tersebut sering dinyanyikan oleh ibu sebagai caregiver. Sambil bernyanyi bersama, ibu menunjuk bagian tubuh yang dimaksud. Selain menambah kosakatanya, aktivitas ini ternyata dapat menghibur individu autis, lewat bernyanyi ibu bisa 
mengamati sejauh apa daya tangkapnya dalam mengingat, selain itu dengan bernyanyi bersama meningkatkan keterkaitan batin antara ibu dan anak serta dapat berpengaruh terhadap psikologi anak, anak menjadi jarang sekali murung dan emosional.

\section{Saat Mandi}

Ketika sedang memandikan, seluruh bagian tubuh seperti rambut, telinga, leher, dada, tangan, paha, hingga jari-jari kaki tentu dibersihkan. Pada saat mandi, saat yang tepat untuk mengenalkan anggota tubuh kepada individu autis, karena dilakukan melalui cara yang menyenangkan, dilakukan pada tempat yang sesuai serta waktu yang tepat. Hal tersebut caregiver (ibu) manfaatkan agar individu autis bebas mengeksplorasi bagian-bagian dalam tubuhnya. Ketika individu autis mengeksplorasi, ibu menjawab setiap pertanyaan yang merupakan bentuk keingintahuannya, hal tersebut ibu jadikan indikator untuk menilai aspek sensorik dan motorik, setelah itu ibu membiarkan individu autis menyebutkan nama anggota tubuh yang perlu dibersihkan saat mandi. Tidak hanya itu, melalui permainan ini individu autis juga akan menyadari betapa pentingnya menjaga kebesihan anggota tubuh, selain itu ibu pun menanamkan bagian tubuh mana yang boleh dan tidak boleh disentuh oleh orang lain serta waktu dan tempat yang tepat dalam kondisi tidak berbusana.

\section{Bermain dengan cermin dan stiker}

Bermain dengan cermin adalah salah satu cara menyenangkan yang bisa dilakukan di rumah. Pertama-tama, ibu menyiapkan cermin agar individu autis bisa melihat seluruh tubuhnya dengan jelas.Kemudian caregiver (ibu) menempelkan stiker bergambar lucu pada kakinya. Ibu bertanya sambil berkaca, "Di mana mama tempel stiker bergambar kelinci?" ibu mengarahkan individu autis agar melihat ke cermin, lalu biarkan individu autis menunjuk stiker tersebut, cara ini ibu lakukan berulang-ulang hingga individu autis dapat mengucapkan "di kakiku!" walaupun terbata-bata, setiap individu autis dapat menjawab, ibu selalu memberi pujian yang ternyata dengan pujian dan pelukan yang sering diberikan ibu, individu autis mengalami perkembangan yang membanggakan.

\section{Story telling}

Ibu sering membelikan buku-buku bergambar tentang anggota tubuh dan fungsinya.Ibu selalu membacakan dan sering bercerita sambil beraktivitas berdua dengan anaknya, seperti "ibuhendak membeli susu, kita pergi yuk nak, jangan lupa kakinya dipakaikan sepatu dulu agar tidak terkena batu". Hal tersebut, walaupun sederhana ternyata mampu menciptakan pemahaman terhadap individu autis, apabila hendak keluar rumah harus menggunakan alas kaki dan dipakaikan dikaki.

\section{Bermain peran}

Ibu suka mengajak anaknya yang individu autis bermain dokter-dokteran, bagian tubuh mana yang sakit, bagian tubuh mana yang harus diobati. Hal ini ibu lakukan untuk mengenalkan anggota tubuh. Ibu berpura-pura sakit di tangan, ibu mengeluh sakit, ibu membiarkan individu autis merespon. Pada awalnya anak tidak merespon, ibu membantu dengan mengucapkan bagian tubuhnya yang sakit. Hal itu ibu coba pada anggota tubuh yang lain, awalnya anak merespon hanya "apa ibu yang sakit" ibu jawab "kaki", lalu sambil mengulang di anggota tubuh yang sama, setelah dinilai anak sudah paham, ibu mencoba ke anggota tubuh yang lain.

Ternyata cara yang digunakan oleh caregiver (ibu) kasus pertama sama dengan apa yang dilakukan oleh [3] dan sejalan dengan yang diungkapkan oleh [1], [4], 
[5], [6], tetapi oleh caregiver pada kasus pertama dimodifkasi dengan menyesuaikan kondisi anaknya, dan berpatokan pada [7] dan [8] terkait apa saja yang harus dipahami oleh anaknya tentang anggota tubuh. Selain itu, ibu pun mempelajari cara bagaimana berkomunikasi yang baik. Hal ini pun sejalan dengan teori bahwa kemandirian seorang individu autis tergantung dari kualitas komunikasi yang dibangun oleh orang tua terutama ibu [9]. Bagi caregiver (ibu) pada kasus pertama, anak merupakan harta yang paling berharga baginya, normal ataupun autistik, ibu selalu berpikir anaknya normal, karena berdasarkan pencarian informasi yang dilakukan, autistik dapat disembuhkan dan diminimalisir apabila ditangani dengan baik, sehingga ibu selalu memperlakukan seperti individu normal. Hal ini pun diungkapkan oleh [2]. Caregiver individu autis pada kasus pertama dalam hal ibu mulai memperkenalkan anggota tubuh, perbedaan jenis kelamin, cara membersihkan anggota tubuh, anggota tubuh yang boleh dipegang atau sentuh dan anggota tubuh yang tidak boleh disentuh atau pegang, yang tujuannya agar anak mereka mandiri dan dapat terhindar dari pelecehan seksual.

Pada kasus kedua, caregiver (ibu) lebih pasif dibandingkan dengan kasus pertama. Guru yang memperkenalkan anggota tubuh sejak dini. Dari pihak caregiver dalam hal ini ibu tidak menjadikan dirinya sebagai role model, beliau sibuk menyalahkan, karena gagal mendapatkan anak yang normal. Sehingga hasil yang didapatkan individu autis tidak dapat maksimal, waktu kebersamaan ibu dan anak tidak dapat dimanfaatkan secara maksimal, maka pengajaran dan pemahaman awal ke individu autis pun tidak optimal. Maka akibatnya diperoleh perilaku individu autis yang suka menyentuh dan memainkan organ-organ vital serta suka menyentuh angota tubuh teman sebayanya.

\section{SIMPULAN}

1. Peran caregiver dapat optimal jika memiliki 3 tahap pengetahuan, yaitu pengetahuan pada saat anaknya teridentifikasi autisme, pengetahuan tentang bagaimana perkembangan anaknya dan pengetahuan orangtua tentang pemberian pendidikan seks pada anaknya, memberikan asuhan kasih sayang dan berperilaku sebagai model bagi anaknya.

2. Caregiver yang terlatih akan menghasilkan individu yang mandiri, paham konsep "umum"/"pribadi" terkait anggota tubuhnya, dapat menunjukkan perilaku pantas dan tidak pantas terkait perilaku yang berhubungan dengan perbedaan jenis kelamin serta perbedaan anggota tubuh antara perempuan dan laki-laki. Selain itu, individu autis memiliki etika bermasyarakat, seperti sopan santun dan tata karma dalam berbicara dan bertamu.

\section{DAFTAR PUSTAKA}

[1] M. U. Lubis. Penyesuaian Diri Orang Tua yang Memiliki Anak Autis. Tesis. USU Repository. Medan, 2009.

[2] D. Puspita. Untaian Duka Taburan Mutiara: Hikmah Perjuangan Ibunda Anak Autistik. Bandung: Qanita, 2004.

[3] D. Puspita. Peran Keluarga: pada Penanganan Individu Autistic Spectrum Disorder, 2003. [Online]. Terdapat: http://puterakembara.org/rm/pera n_ortu.htm. diakses: 19 Januari 2014.

[4] G. Aulianingtias. Pelatihan Keterampilan Pengasuhan untuk Meningkatkan Pemahaman Orang Tua tentang Anak. 
Universitas Islam Indonesia. Yogyakarta, 2008.

[5] S. Biddulph. Mendidik Anak dengan Cinta: Petunjuk bagi Orang Tua agar Anak menjadi Bahagia. Jakarta: Gramedia Pustaka Umum, 2006.

[6] Hando. Autisma: Petunjuk Praktis dan Pedoman Materi untuk Mengajar Anak Normal, Autis dan Perilaku Lain. Jakarta: Bhuana Ilmu Populer, 2003.

[7] Ranuh IGN. Ilmu Kesehatan Anak. Jakarta: DepKes RI, 1988.

[8] W. Sears. The Successful Child. Jakarta: Bening Publishing, 2006.

[9] Seto. Membangun Komunikasi Bijak Orang Tua dan Anak. Jakarta: Kompas, 2007. 